Check for updates

Cite this: RSC Adv., 2019, 9, 34330

Received 17th July 2019

Accepted 11th October 2019

DOI: $10.1039 / c 9 r a 05475 h$

rsc.li/rsc-advances

\section{Effects of octamethylcyclotetrasiloxane grafting and in situ silica particle generation on the curing and mechanical properties of a styrene butadiene rubber composite}

\begin{abstract}
Changjie Yin (DD * and Qiuyu Zhang
The reinforcement of octamethylcyclotetrasiloxane $\left(D_{4}\right)$ grafted styrene butadiene rubber $\left(S B R-g-D_{4}\right)$ with in situ generated silica was performed using the sol-gel reaction of tetraethoxysilane (TEOS) in latex. The characterization of SBR-g- $D_{4}$ and in situ generated silica reinforced SBR-g- $D_{4}$ was investigated by Fourier transform infrared spectroscopy (FTIR), X-ray photoelectron spectroscopy (XPS) and Raman spectroscopy. The grafting efficiency of the styrene butadiene rubber (SBR) was determined by a gravimetric method. It was found that the constant silicon content and the grafting efficiency of SBR were $1.72 \%$ and $0.13 \mathrm{wt} \%$ when the weight ratio of $\mathrm{D}_{4}$ to SBR was 0.20 . The effects of the $\mathrm{D}_{4}$ and in situ generated silica content on the curing characteristics, mechanical properties and morphology of SBR latex were investigated. The mechanical properties of in situ generated silica reinforced SBR-g-D vulcanizates were improved significantly compared to raw SBR vulcanizate when the in situ generated silica content was $18.05 \%$. Compared with silica reinforced SBR-g- $D_{4}$, the tensile strength, wet skid resistance and rolling resistance of the in situ generated silica reinforced SBR- $g-D_{4}$ were better. This is because of the higher crosslinking degree in the SBR-g- $D_{4}$ matrix and the strong chemical bond between SBR-g- $D_{4}$ molecular chains and in situ generated silica. Scanning electron microscopy analysis revealed good silica filler dispersion in all the reinforced SBR-g-D 4 vulcanizates.
\end{abstract}

\section{Introduction}

As previously reported,,$^{1-3}$ silica $\left(\mathrm{SiO}_{2}\right)$ is considered to be a good candidate for the substitution of the traditional carbon black in the application of green tire manufacturing, because the tire treads filled by silica have better wet skid resistance, low rolling resistance and better wear resistance than carbon. ${ }^{4,5}$ However, $\mathrm{SiO}_{2}$ has a high polarity and hydrophilic surface due to silanol groups on its surface, ${ }^{6}$ which leads to poor interactions between $\mathrm{SiO}_{2}$ and SBR. ${ }^{7}$

In order to solve this problem, the grafting modification of SBR is a promising and effective approach. ${ }^{8}$ In previous work, many studies focused on grafting rubber using the vinyl monomers, such as maleic anhydride (MA), ${ }^{9}$ vinyl alcohol $(\mathrm{VA}){ }^{10}$ stearyl methacrylate, ${ }^{11}$ methyl methacrylate (MMA), ${ }^{12}$ glycidyl methacrylate (GMA), ${ }^{13}$ acrylonitrile (AN) ${ }^{14}$ styrene (St) ${ }^{15}$ vinyltriethoxysilane ${ }^{16}$ and so forth. The methods for the preparation of grafted rubber include thermal graft copolymerization $^{17-20}$ and irradiation grafting polymerization..$^{21-23}$ Second, the generation of the in situ silica in the rubber matrix by the

Xi'an Key Laboratory of Functional Organic Porous Materials, Department of Applied Chemistry, School of Science, Northwestern Polytechnical University, Xi'an, Shaanxi 710072, People's Republic of China.E-mail: yinchangjie@nwpu.edu.cn sol-gel reaction of TEOS is another effective technology, and this technology has been used in various rubber forms, such as solid rubber, ${ }^{24,25}$ rubber latex ${ }^{26,27}$ and rubber solution. ${ }^{28-30}$ Third, combining the grafted rubber with sol-gel technology using TEOS to improve the properties of silica/rubber compounds is the most effective method of all. Sittiphan et al. ${ }^{31}$ reported the filling of styrene (St) grafted natural rubber (St-NR) with in situ generated silica which was performed using the sol-gel reaction of TEOS, where transmission electron microscopy results revealed that the in situ silica particles were small $(\sim 40 \mathrm{~nm}$ in diameter) and well dispersed. The in situ silica filling of MMANR via the solid rubber and rubber latex methods has been reported. ${ }^{32}$ Although the use of vinyl monomer graft polymerization modified rubber can improve the compatibility between silica and rubber, the chemical interaction between rubber and $\mathrm{SiO}_{2}$ has not been greatly improved. Zhang et al. ${ }^{33,34}$ discussed the in situ silica reinforcement of VTES grafted SBR (SBR-gVTES) by the sol-gel process in latex; it was reported that the increased tensile strength was due to the chemical interaction between silica and SBR in the in situ reinforced SBR- $g$-VTES. However, with the grafting polymerization of the VTES onto the SBR in latex, the hydrolysis and condensation of the VTES may destroy the stability of SBR latex. Therefore, it is highly necessary to use unhydrolyzable cyclosiloxanes to obtain the grafted 
SBR. Recently, different methods of grafting octamethylcyclotetrasiloxane $\left(\mathrm{D}_{4}\right)$ onto polyacrylate by emulsion polymerization have been reported. Liang et al. ${ }^{35}$ prepared a new core-shell silicon-containing fluoroacrylate by the $\mathrm{D}_{4}$ ring-opening polymerization in the presence of the fluoroacrylate latex using ammonium persulfate (APS) as the initiator. Jiang et al. ${ }^{36}$ also thoroughly studied the kinetics of the ring-opening polymerization of $\mathrm{D}_{4}$ in emulsion, showing that the content of $\mathrm{D}_{4}$ molecules at the interface could cause an increase in the polymerization rate. Based on these two articles, it is possible to obtain modified polymers by ring-opening polymerization of $\mathrm{D}_{4}$ in emulsion.

As a result, in this study, the SBR- $g-\mathrm{D}_{4}\left(\mathrm{D}_{4}\right.$ grafted SBR) was firstly synthesized using the grafting polymerization reaction of the $\mathrm{D}_{4}$ onto the SBR molecular chains in the SBR latex. The effects of the $\mathrm{D}_{4}$ content on the silica content, curing characteristics and mechanical properties of the SBR- $g$ - $\mathrm{D}_{4}$ were investigated to find the optimal conditions (defined as a good balance between curing characteristics and mechanical properties at the highest grafting ratio of SBR with the lowest added mass of $\mathrm{D}_{4}$ ). The SBR- $g$ - $\mathrm{D}_{4}$ latex was then mixed with various amounts of TEOS at $50{ }^{\circ} \mathrm{C}$. Subsequently, SBR composites with a different silica content were obtained after the in situ sol-gel of TEOS. The effects of the mass of TEOS on the silica content, utilization of the TEOS, curing characteristics and mechanical properties of in situ generated silica reinforced SBR- $g$ - $\mathrm{D}_{4}$ vulcanizates were systematically discussed. Finally, the morphology of the in situ silica filled $S B R-g-D_{4}$ vulcanizates was characterized.

The schematic representation of the in situ silica generated in the SBR- $g-\mathrm{D}_{4}$ matrix after graft copolymerization is shown in Scheme 1. The occurrence of the $\mathrm{D}_{4}$ grafting onto the SBR backbone (Scheme 1a) and the formation of the in situ silica via the sol-gel reaction of TEOS in the TEOS swelled SBR- $g$-D $D_{4}$ latex, for sol-gel reaction after graft copolymerization, are depicted. The chemical bond could be formed between the in situ generated silica particles and SBR- $g-\mathrm{D}_{4}$ molecular chains (Scheme 1b).

\section{Experimental}

\subsection{Materials}

Silica was purchased from Changtai Micro-Nano Chemistry Co., Ltd., China. The primary silica particles were of 10-20 nm diameter and with a $190 \mathrm{~m}^{2} \mathrm{~g}^{-1}$ to $200 \mathrm{~m}^{2} \mathrm{~g}^{-1}$ surface area. The styrene butadiene rubber (SBR1502) was kindly provided by Lan Zhou Petroleum Chemical Industrial Co., Ltd., China. Octamethylcyclotetrasiloxane $\left(\mathrm{D}_{4}\right)$ was provided by Guangzhou Double Peach Fine Chemical Co., Ltd., China. Tetraethoxysilane (TEOS, CP) was purchased from Sinopharm Chemical Reagent Co., Ltd., China. Potassium persulfate (KPS, CP) was supplied by Tianjin Shan Pu Chemical Co., Ltd., China. Sulfur, zinc oxide (ZnO), stearic acid (SA), $N$-cyclohexyl-benzothiazyl-sulfenamide (CBS, purity > 97\%), $N$-(1,3-dimethylbutyl)- $N^{\prime}$-phenyl- $p$-phenylenediamine (DPG, purity > 97\%), 2,2,4-trimethyl-1,2dihydroquinoline (8PPD), methyltrialkylammonium chloride (AM-2) and the condensation product of dicyandiamide and formaldehyde (TXD), both industry grade, were provided by Lan Zhou Petroleum Chemical Industrial Co., Ltd., China.

\subsection{Preparation of $\mathrm{D}_{4}$ grafted SBR (SBR- $\left.g-\mathrm{D}_{4}\right)$}

The graft reactions were carried out in a four neck $500 \mathrm{~mL}$ round bottom flask reactor with agitation of $100 \mathrm{rpm}$ under nitrogen atmosphere. In each reaction, $200.00 \mathrm{~g}$ SBR latex (40.00 g dry SBR) was added first while stirring at $80{ }^{\circ} \mathrm{C}$ over $30 \mathrm{~min}$ to remove the oxygen. The initiator KPS (1.00 $\mathrm{g}$ KPS was dissolved in $9.00 \mathrm{~g} \mathrm{H}_{2} \mathrm{O}$ ) was then added in turn to the latex over $60 \mathrm{~min}$, while at the same time, the $\mathrm{D}_{4}$ (varying from $0.00 \mathrm{~g}$, $2.00 \mathrm{~g}, 4.00 \mathrm{~g}, 6.00 \mathrm{~g}, 8.00 \mathrm{~g}, 10.00 \mathrm{~g}$ ) was slowly dropped into the latex at a rate of $20 \mathrm{mg} \mathrm{min}{ }^{-1}$ until completion; stirring was continued for 1 hour to obtain the grafted SBR latex (SBR- $g$ - $D_{4}$ latex). Hydroquinone was added to stop the reaction. 24 hours later $2.00 \mathrm{~g}$ SBR- $g$ - $\mathrm{D}_{4}$ latex samples were poured on a vessel and dried in an oven at $70^{\circ} \mathrm{C}$ for $48 \mathrm{~h}$ to remove water and unreacted monomers to obtain the dry SBR- $g$ - $\mathrm{D}_{4}$ which was used for infrared and thermogravimetric analysis.

\subsection{Sol-gel reaction of TEOS in the SBR-g-D $\mathrm{D}_{4}$ latex}

In this study, the TEOS was added after the graft copolymerization. The TEOS was slowly dropped into the SBR- $g-\mathrm{D}_{4}$ latex at a rate of $0.50 \mathrm{~g} \mathrm{~min}^{-1}$ at $50{ }^{\circ} \mathrm{C}$ until completion; the conditions for the sol-gel reaction of TEOS in SBR- $g$ - $\mathrm{D}_{4}$ latex are summarized in Table 1 . The antioxidant $(0.010 \mathrm{~g} 8 \mathrm{PPD})$ and coagulants (0.020 $\mathrm{g} \mathrm{AM-2,} \mathrm{and} 0.001 \mathrm{~g}$ TXD) were then added into the in situ sol-gel SBR- $g$ - $\mathrm{D}_{4}$ latex by dropping in turn over $2 \mathrm{~min}$, and then the SBR- $g-\mathrm{D}_{4}$ rubber was coagulated from the latex. Lastly, the SBR- $g-\mathrm{D}_{4}$ rubber was dried under vacuum at $60{ }^{\circ} \mathrm{C}$ for $24 \mathrm{~h}$.

\subsection{Preparation of silica reinforced SBR vulcanizates and the in situ generated silica reinforced $\mathrm{SBR}-g$ - $\mathrm{D}_{4}$ vulcanizates}

The compounding compositions of the silica and in situ generated silica reinforced SBR- $g-\mathrm{D}_{4}$ vulcanizates are described in Table 2. The in situ generated silica reinforced SBR- $g-\mathrm{D}_{4}$ vulcanizates were obtained using a two-roll mill (X(S)-160 type at room temperature, Shanghai Rubber Machinery Factory, China). First, the in situ formed silica reinforced SBR- $g-\mathrm{D}_{4}$ rubber, $\mathrm{ZnO}$ and SA were mixed together by a two-roll mill. Second, the S, and the vulcanization accelerators CBS and DPG, were added into the same mill. Third, the rubber composites were vulcanized at $160{ }^{\circ} \mathrm{C}$ according to the optimum cure time $\left(t_{90}\right)$ measured by a rubber rheometer in a press at $10 \mathrm{MPa}$ to obtain the $2.00 \mathrm{~mm}$ thick films of vulcanized rubber to be used in the mechanical properties analysis.

\subsection{Characterization}

2.5.1 Silicon content and grafting efficiency of SBR. Ungrafted SBR was washed out in a Soxhlet extractor with 60$80{ }^{\circ} \mathrm{C}$ boiling point petroleum ether for $24 \mathrm{~h}$, and the residue was then extracted in acetone for $24 \mathrm{~h}$ to remove the free polymers of $\mathrm{D}_{4}$. The grafting efficiency of $\mathrm{D}_{4}(w)=$ practical silicon content $\left(w_{2}\right) /$ theoretical silicon content $\left(w_{1}\right)$. The formulae for calculating $w_{1}$ and $w_{2}$ are as follows: 


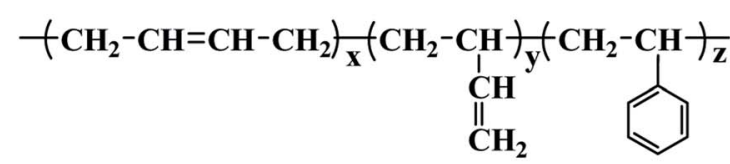

SBR

r Grafting
polymerization

a<smiles>C[Si]1(C)O[Si](C)(C)O[Si](C)(C)[Si](C)(C)O1</smiles>

$\left.\left.+\mathrm{CH}_{2}-\mathrm{CH}=\mathrm{CH}-\mathrm{CH}_{2}\right)_{x}+\mathrm{CH}_{2}-\mathrm{CH}_{1}\right)_{\mathbf{y}}\left(\mathrm{CH}_{2}-\mathrm{CH}\right)_{\mathrm{z}}$

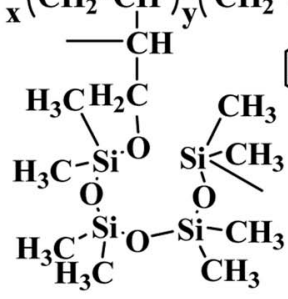<smiles>C[C](C)c1ccccc1</smiles>

SBR-g-D 4

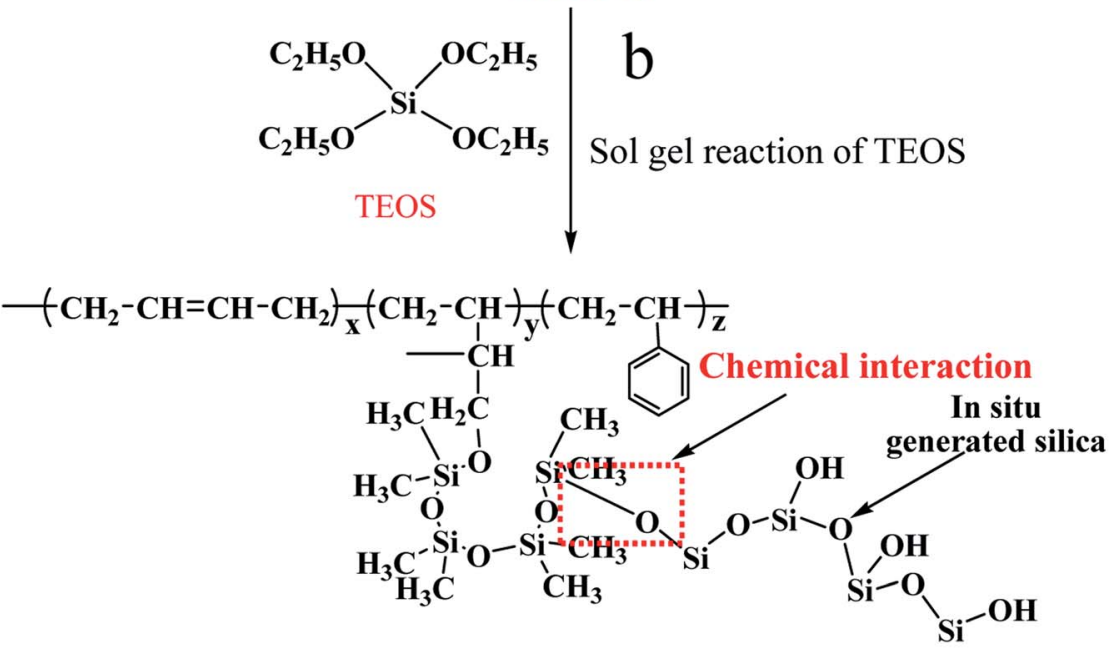

in-situ silica reinforced SBR-g-D

Scheme 1 Possible mechanism for the interactions and bonding between SBR- $g-D_{4}$ and silica.

$$
\begin{gathered}
w_{1}=\frac{m_{2} \times 4 \times 28}{296 \times m_{1}} \\
w_{2}=\frac{m_{4} \times 28}{m_{3} \times 60} \\
w_{0}=\frac{m_{2} \times w}{m_{2} \times w+40.00}
\end{gathered}
$$

$w_{0}$ represents the grafting efficiency of SBR; $m_{1}, m_{2}$ represent the total mass of the SBR-g- $\mathrm{D}_{4}$ and $\mathrm{D}_{4}$, respectively; $m_{3}$ denotes the weight of SBR-g- $\mathrm{D}_{4}$ for muffle furnace burning; $m_{4}$ denotes the weight of the ashes (the residue of SBR-g- $\mathrm{D}_{4}$ in a muffle furnace under $700{ }^{\circ} \mathrm{C}$ for $6 \mathrm{~h}$, washed by diluted hydrochloric acid and water three times, respectively). 4, 40, 28, 60 and 296 are the number of silicon atoms in $\mathrm{D}_{4}$, the quality of dry rubber, the molecular weight of silicon, silica and $\mathrm{D}_{4}$, respectively.
2.5.2 Silica content and utilization of silica in the in situ formed silica reinforced SBR-g-D $-\mathbf{D}_{\mathbf{4}}$. The silica content and utilization efficiency of TEOS were determined using a muffle furnace under $700{ }^{\circ} \mathrm{C}$ for $6 \mathrm{~h}$. Silica content $\left(w_{3}\right)=m_{6} / m_{5}$, utilization efficiency of TEOS $=$ practical silica content as

Table 1 Conditions for the sol-gel reaction of TEOS in the SBR-g-D latex

\begin{tabular}{lll}
\hline Condition number & TEOS content $(\mathrm{g})$ & Temperature $\left({ }^{\circ} \mathrm{C}\right)$ \\
\hline 1 & 0.00 & 50 \\
2 & 2.00 & 50 \\
3 & 4.00 & 50 \\
4 & 6.00 & 50 \\
5 & 8.00 & 50 \\
6 & 10.00 & 50
\end{tabular}


Table 2 Formulations for the rubber compounding, in parts by weight per hundred parts (phr)

\begin{tabular}{|c|c|c|c|}
\hline Ingredient & Content (phr) & Content (phr) & Content (phr) \\
\hline Pristine SBR & 100.00 & & \\
\hline SBR-g- $-\mathrm{D}_{4}$ rubber & & 100.00 & \\
\hline Silica & 0 & Varied from $0,4.80,7.90,9.32,13.70,18.05$ & 0 \\
\hline $\mathrm{ZnO}$ & 3.00 & 3.00 & 3.00 \\
\hline SA & 1.00 & 1.00 & 1.00 \\
\hline $\mathrm{S}$ & 2.00 & 2.00 & 2.00 \\
\hline
\end{tabular}

formed by TEOS $\left(w_{5}\right)$ /theoretical silica content as formed by TEOS $\left(w_{4}\right)$. The formulae for calculating $w_{4}, w_{5}$, and $w_{6}$ are as follows:

$$
\begin{gathered}
w_{4}=\frac{m_{7} \times 60 / 208}{200 \times 20 \%+m_{7} \times 60 / 208} \\
w_{6}=\frac{m_{8} \times 60 / 297}{200 \times 20 \%+m_{8} \times 60 / 297} \\
w_{5}=w_{3}-w_{6} \times w
\end{gathered}
$$

where $m_{5}, m_{6}$ are the weight of in situ generated silica reinforced SBR- $g$ - $\mathrm{D}_{4}$ and the weight of the residue of $i n$ situ generated silica reinforced SBR- $g$ - $\mathrm{D}_{4}$ in a muffle furnace under $700{ }^{\circ} \mathrm{C}$ for $6 \mathrm{~h}$, respectively. $m_{7}$ and $m_{8}$ are the weight of TEOS and $\mathrm{D}_{4}$, respectively. 60, 297, 208, and $w$ are the molecular weights of $\mathrm{SiO}_{2}, \mathrm{D}_{4}$, TEOS, and the grafting efficiency of $\mathrm{D}_{4}$, respectively. Bound rubber was measured as a percentage of insoluble rubber in total rubber for the differing silica content.

2.5.3 ATR-FTIR analysis. The attenuated total reflectanceFourier transform infrared (ATR-FTIR) spectra of SBR, SBR- $g$ -

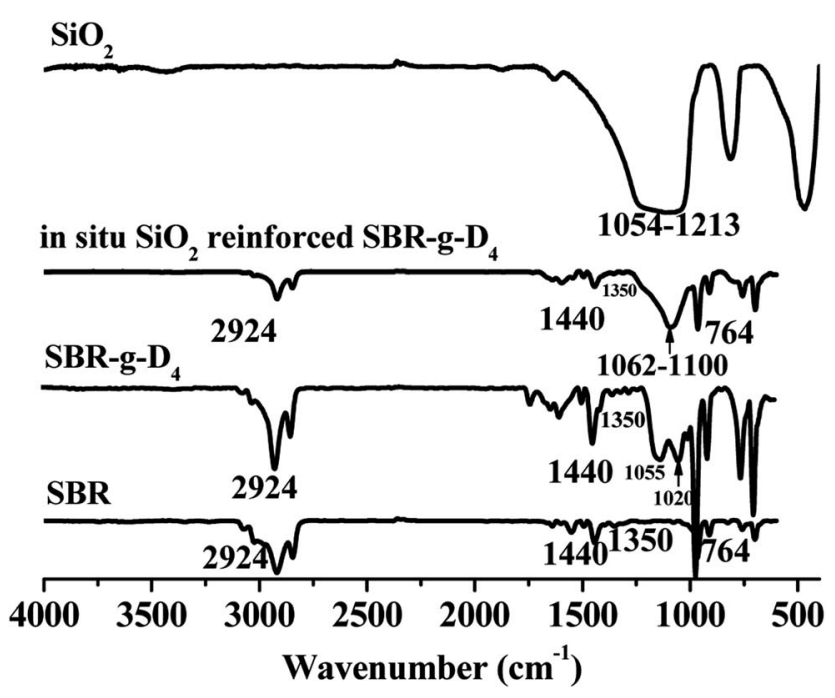

Fig. 1 FTIR spectra of SBR, SBR-g- $\mathrm{D}_{4}$, in situ generated $\mathrm{SiO}_{2}$ reinforced SBR $-g-\mathrm{D}_{4}$ and $\mathrm{SiO}_{2}$.
$\mathrm{D}_{4}$ and in situ generated silica reinforced SBR- $g-\mathrm{D}_{4}$ were characterized using a Tensor-37 FTIR spectrometer (Bruker Optics Inc, Germany) at room temperature. The FTIR spectrum of $\mathrm{D}_{4}$ was determined in the range of $400-4000 \mathrm{~cm}^{-1}$ with 32 scans.

2.5.4 XPS analysis. The XPS analysis of SBR and SBR- $g-\mathrm{D}_{4}$ rubber samples was conducted using a Kratos Axis Ultra X-ray photoelectron spectrometer fitted with a monochromatic Al $\mathrm{K} \alpha \mathrm{X}$-ray source $(1487 \mathrm{eV})$ operating on a spot size of $300 \mu \mathrm{m} .{ }^{37}$

2.5.5 Raman spectroscopy. The Raman spectra of SBR and SBR- $g-\mathrm{D}_{4}$ were recorded using a WITec alpha 300RA confocal Raman spectrometer. ${ }^{38}$

2.5.6 Curing characteristics. The curing time $\left(t_{90}\right)$, maximum torque $(\mathrm{MH})$ and minimum torque $(\mathrm{ML})$ of rubber vulcanizate composites were studied using a Moving Die Rheometer (MDR) JC-2000E (JiangDu JingCheng Test Instruments Factory, China) at $160{ }^{\circ} \mathrm{C}$ according to ASTM D 2084-95.

2.5.7 Mechanical properties. The mechanical properties of the $2 \mathrm{~mm}$ thick cured films of the rubber vulcanizate composites were measured using a SANS-CMT 5105 electrical tensile tester (Shenzhen SANS Test Machine Co., China) in accordance with ASTM D 412 using dumbbell-shaped test specimens at a crosshead speed of $500 \mathrm{~mm} \mathrm{~min}^{-1}$.

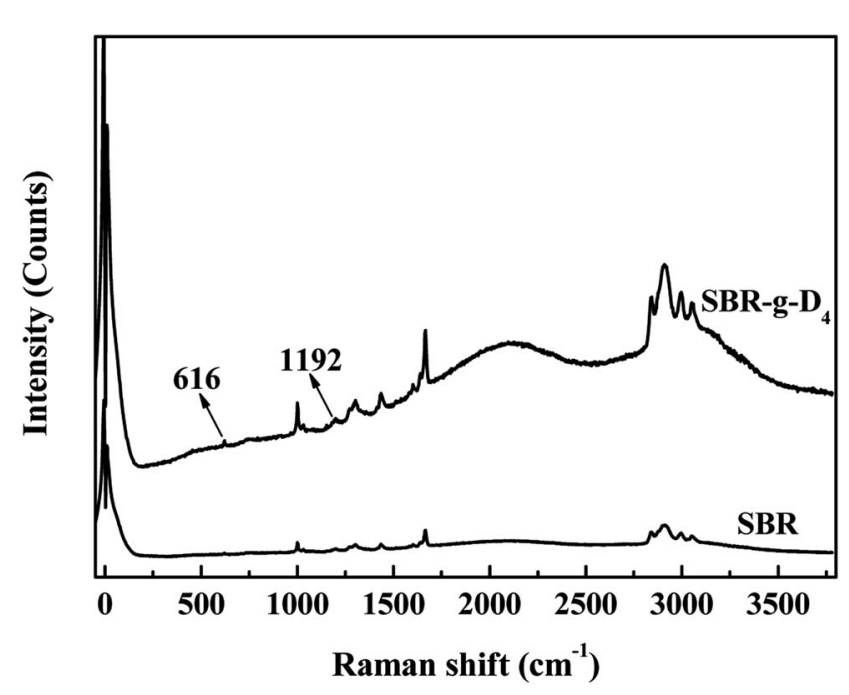

Fig. 2 Raman spectra of SBR and SBR-g-D . 


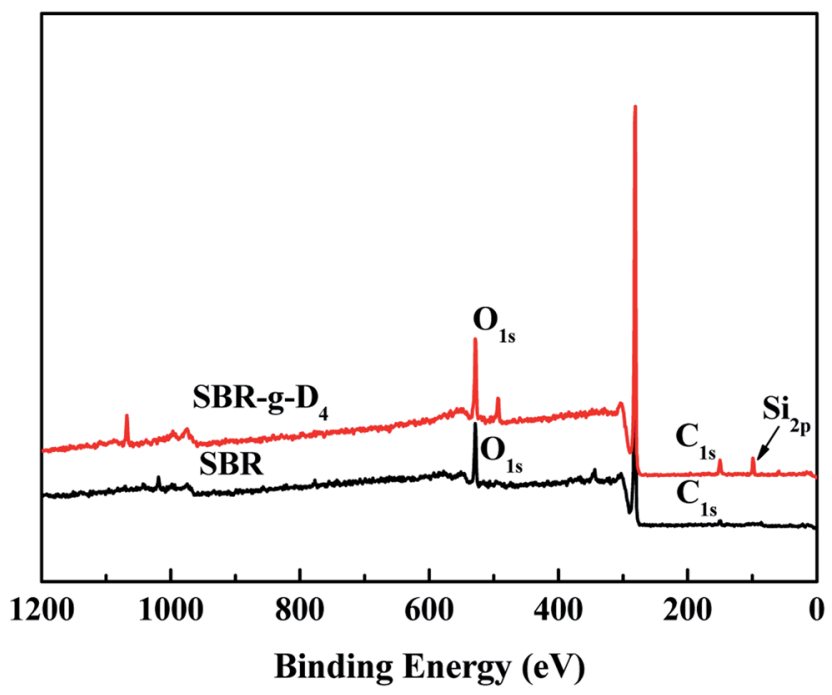

Fig. 3 XPS spectra of SBR and SBR-g-D .

2.5.8 Dynamic mechanical analysis. Dynamic mechanical analysis was performed using the DMA/SDTA861e (MettlerToledo, Switzerland) in the tension mode, at a heating rate of $5^{\circ} \mathrm{C} \min ^{-1}$ from $-50{ }^{\circ} \mathrm{C}$ to $110{ }^{\circ} \mathrm{C}$. The specimens (size $30 \times 5 \times$ $2 \mathrm{~mm}^{3}$ ) were cut from the center of the samples.

2.5.9 Scanning electron microscopy (SEM). Examination of the tensile fracture surfaces of SBR and the in situ formed silica reinforced SBR- $g-D_{4}$ composites was conducted using SEM with a JSM-6700F scanning electron microscope (Japan Electron Optics Laboratory, Japan) on gold-coated cryo-fracture surfaces.

\section{Results and discussion}

3.1 Characterization of SBR-g- $-\mathrm{D}_{4}$ and in situ generated $\mathrm{SiO}_{2}$ reinforced SBR- $g-\mathrm{D}_{4}$

FTIR spectra of the pristine SBR, pristine silica, SBR- $g-\mathrm{D}_{4}$, and in situ generated silica reinforced SBR- $g-\mathrm{D}_{4}$ without any crosslinking additives are shown in Fig. 1. For SBR, the absorption

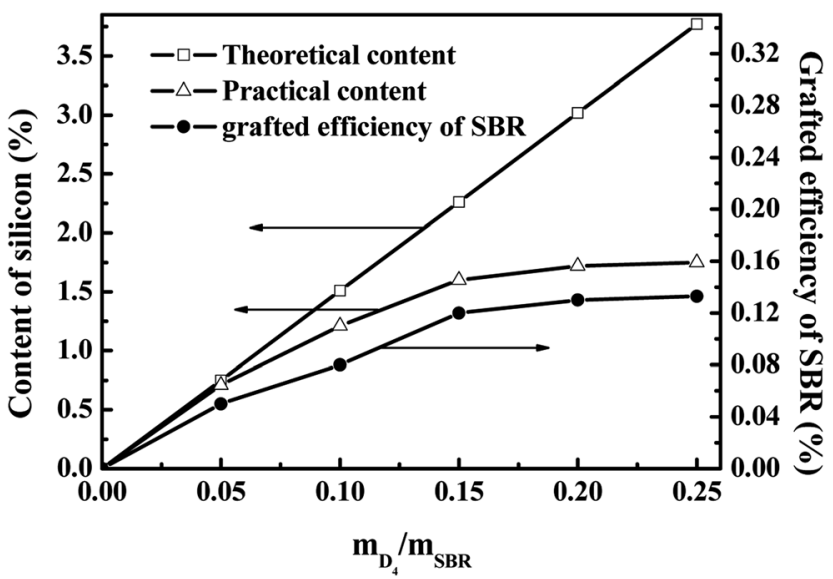

Fig. 4 Effects of the weight ratio of $D_{4}$ to SBR on the silicon content in SBR-g-D . $^{2}$

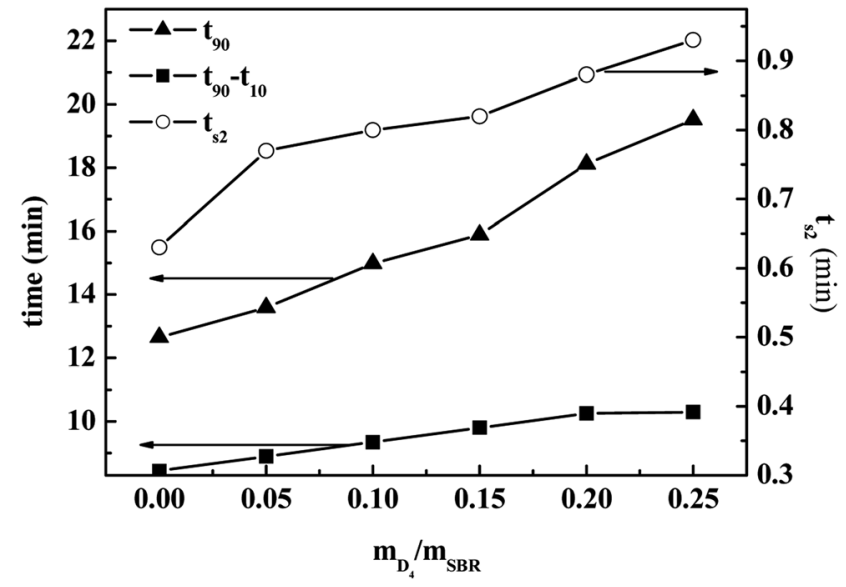

Fig. 5 Effects of the weight ratio of $D_{4}$ to SBR on the cure time $\left(t_{90}\right)$ and scorch time $\left(t_{\mathrm{s} 2}\right)$ of the SBR- $g-D_{4}$ vulcanizates.

peaks appeared at 2924, 1440, 1350 and $764 \mathrm{~cm}^{-1}$, which were identified as the stretching vibration of aliphatic $=\mathrm{C}-\mathrm{H}, \mathrm{C}-\mathrm{H}$ bending of $\mathrm{CH}_{2}, \mathrm{C}-\mathrm{H}$ bending of $\mathrm{CH}_{3}$ and $\mathrm{C}=\mathrm{C}$ bending vibrations, respectively. ${ }^{32}$

Compared with the pristine SBR, the spectrum of the SBR- $g$ $\mathrm{D}_{4}$ shows the same major signals as obtained from $\mathrm{SBR}$, and the additional absorption signals at 1020 and $1055 \mathrm{~cm}^{-1}$ corresponding to the $-\mathrm{Si}-\mathrm{O}-\mathrm{C}-$ and $-\mathrm{Si}-\mathrm{O}-\mathrm{Si}^{-39}$ stretching and vibration are evidence for $\mathrm{D}_{4}$ being present in the SBR- $g-\mathrm{D}_{4}$ grafted copolymer.

Furthermore, the new absorption peaks at $1062-1100 \mathrm{~cm}^{-1}$ are attributed to the $-\mathrm{Si}-\mathrm{O}-\mathrm{Si}-$ stretching of silica generated by the sol-gel reaction of the TEOS in the in situ generated $\mathrm{SiO}_{2}$ reinforced SBR- $g$-D ${ }_{4} \cdot{ }^{40}$ Compared with the absorption peaks of -Si-O-Si- groups at $1054-1213 \mathrm{~cm}^{-1}$ in the pristine silica, the narrower absorption peaks in the $\mathrm{SiO}_{2}$ reinforced SBR- $g-\mathrm{D}_{4}$ may indicate the existence of an interaction between SBR- $g-\mathrm{D}_{4}$ and silica that arises via $\mathrm{D}_{4}$.

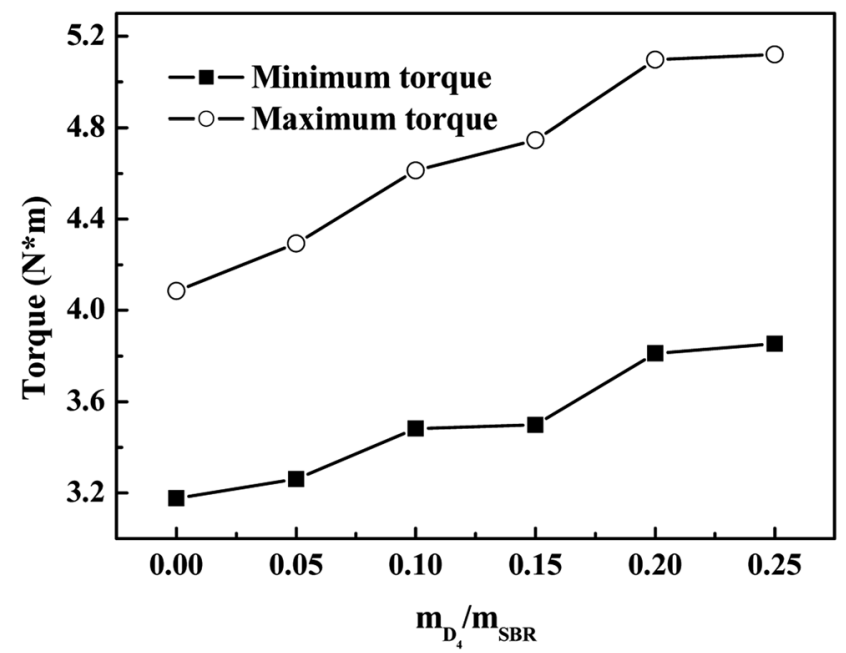

Fig. 6 Effects of the weight ratio of $D_{4}$ to $S B R$ on the maximum torque $(\mathrm{MH})$ and minimum torque $(\mathrm{ML})$ of the SBR-g- $\mathrm{D}_{4}$ vulcanizates. 


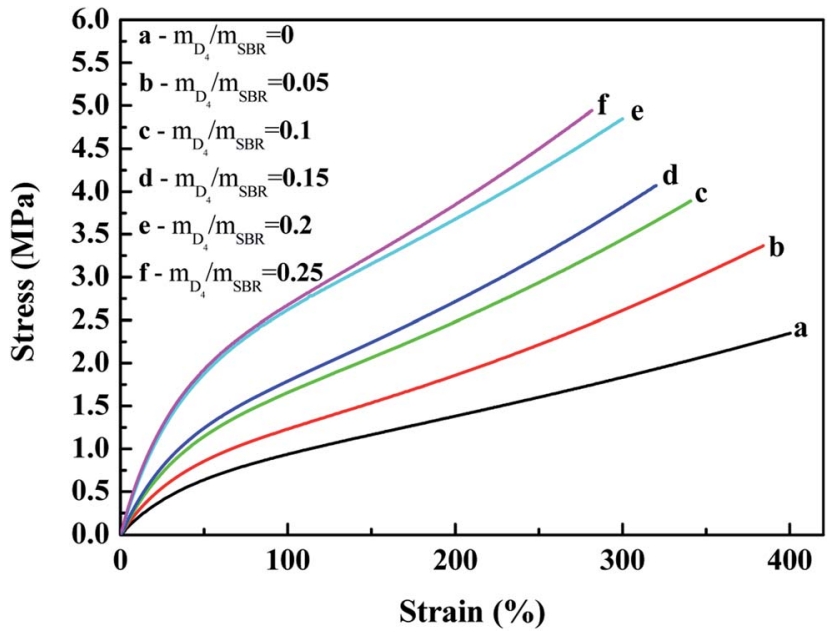

Fig. 7 Effects of the weight ratio of $D_{4}$ to SBR on the stress-strain behavior of the SBR- $g-D_{4}$ vulcanizates.

Raman spectra were obtained to confirm that the $\mathrm{D}_{4}$ was grafted onto the backbone of SBR. The corresponding results are shown in Fig. 2. Compared with the Raman spectrum of SBR, the new peaks at 616 and $1192 \mathrm{~cm}^{-1}$ could be assigned to the bending and asymmetric stretching modes in the $\mathrm{Si}-\mathrm{O}-\mathrm{Si}$ for $\mathrm{D}_{4}$, respectively. ${ }^{41}$ At the same time, the non-polar $-\mathrm{CH}_{3}$ groups are at the Raman shift of $2900-3000 \mathrm{~cm}^{-1}$, and it is shown that the band peak at $2900-3100 \mathrm{~cm}^{-1}$ for the SBR- $g-\mathrm{D}_{4}$ is much stronger than that of SBR, which indicates that a large number of $-\mathrm{CH}_{3}$ groups have been introduced into the molecular chains of the SBR after grafting with $\mathrm{D}_{4}$.

The elemental composition of SBR and SBR- $g-\mathrm{D}_{4}$ samples was analyzed with wide-scan XPS spectra, as shown in Fig. 3. Compared with SBR alone, for the SBR- $g$ - $\mathrm{D}_{4}$ sample, stronger $\mathrm{O}_{1 \mathrm{~s}}$ and $\mathrm{C}_{1 \mathrm{~s}}$ signals were observed, and a new peak at 98-100 eV corresponding to $\mathrm{Si}$ element was also observed for the SBR- $g-\mathrm{D}_{4}$ sample, indicating the successful grafting of $\mathrm{D}_{4}$ onto SBR chains. ${ }^{42}$

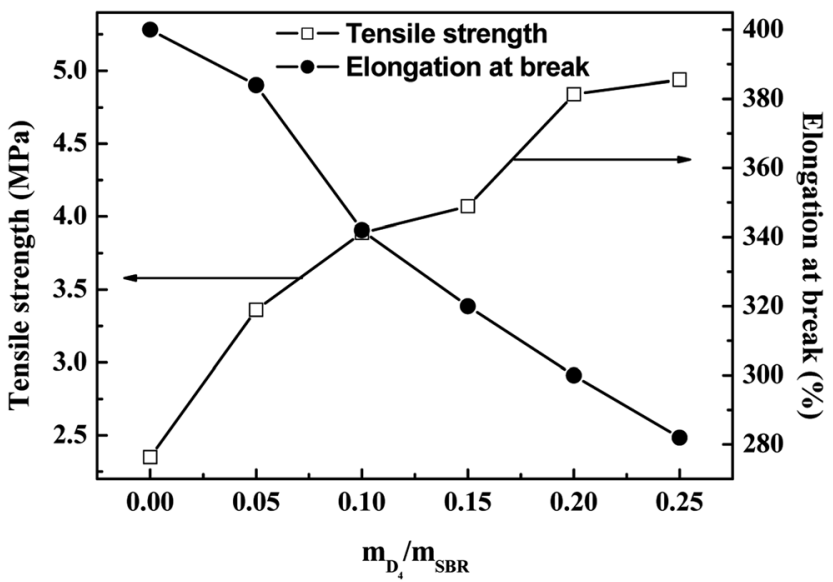

Fig. 8 Effects of the weight ratio of $D_{4}$ to SBR on the tensile strength and elongation at break of the SBR- $g-D_{4}$ vulcanizates.

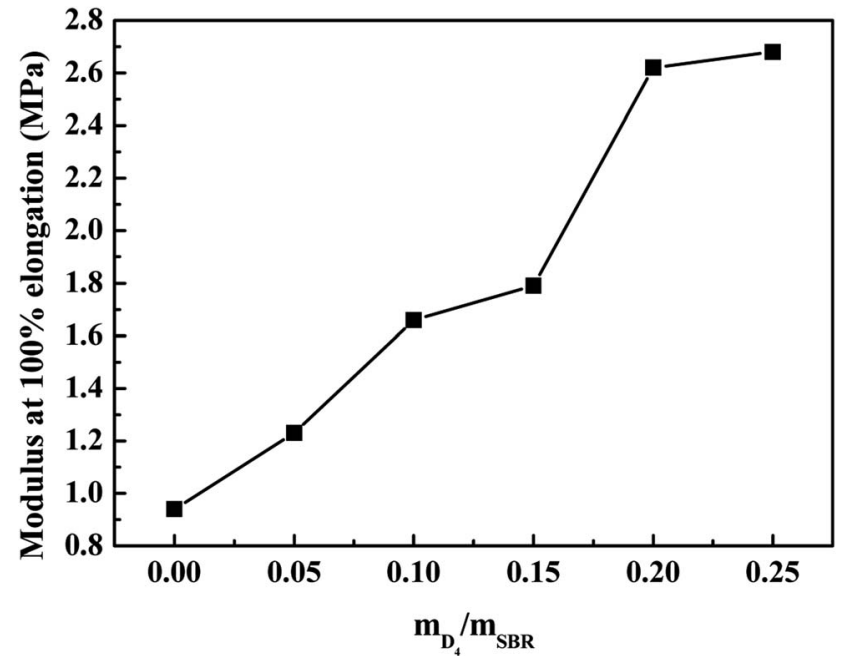

Fig. 9 Effects of the weight ratio of $D_{4}$ to SBR on the modulus at $100 \%$ elongation of the SBR- $g-D_{4}$ vulcanizates.

In this experiment, octamethylcyclotetrasiloxane $\left(\mathrm{D}_{4}\right)$ was chosen to be grafted onto the molecular chains of SBR. From the results of the FTIR, Raman and XPS analysis, the main reaction is the free radical polymerization between the ringopening of $\mathrm{D}_{4}$ with the double bond in SBR as in Scheme 1. The ring-opening polymerization of $\mathrm{D}_{4}$ was initiated by KPS to get the active center in the SBR latex, and then one part of the active center could attack the double bond in the molecular chains of SBR to obtain the SBR- $g$ - $\mathrm{D}_{4}$, and one part of the active center could form ungrafted polyoctamethylcyclotetrasiloxane. Huang et al. also found that polyacrylate modified by polysiloxane latex could be successfully prepared by successive seeding polymerization with the radical polymerization of acrylate and the ring opening polycondensation of $\mathrm{D}_{4} \cdot{ }^{43}$

\subsection{Graft copolymerization of $\mathrm{D}_{4}$ onto SBR latex}

3.2.1 Silicon content in the SBR-g- $\mathrm{D}_{4}$ and grafting efficiency of SBR. The effects of the weight ratio of $D_{4}$ to SBR on the

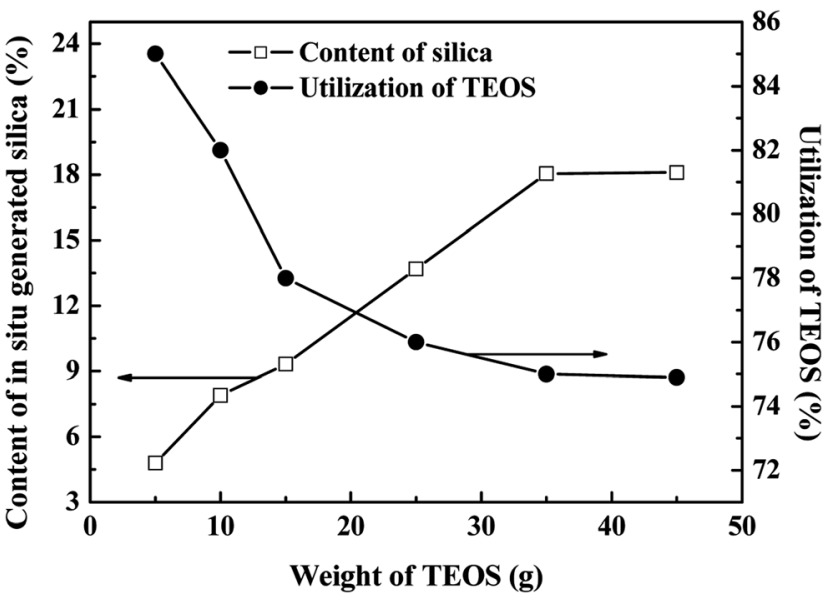

Fig. 10 Effects of the weight of TEOS on the in situ generated silica content and utilization of TEOS. 
Table 3 Effects of in situ generated silica content on the curing time of reinforced SBR- $g-D_{4}$ vulcanizates

\begin{tabular}{llll}
\hline $\begin{array}{l}\text { In situ } \\
\text { generated silica }(\%)\end{array}$ & $t_{\mathrm{s} 2}(\mathrm{~min})$ & $t_{90}(\mathrm{~min})$ & $t_{90}-t_{10}(\mathrm{~min})$ \\
\hline 0 & 0.82 & 15.89 & 8.50 \\
4.8 & 1.13 & 16.41 & 8.98 \\
7.9 & 1.23 & 17.63 & 9.21 \\
9.32 & 1.32 & 18.75 & 9.35 \\
13.7 & 1.56 & 19.34 & 9.48 \\
18.05 & 1.73 & 20.5 & 9.62
\end{tabular}

practical silicon content, theoretical silicon content and grafting efficiency of SBR were studied and are shown in Fig. 4. This shows that the practical silicon content was lower than the theoretical silicon content in the SBR-g- $\mathrm{D}_{4}$; this is due to the free $\mathrm{PD}_{4}$ (polyoctamethylcyclotetrasiloxane) which is increased with increasing the mass ratio of $\mathrm{D}_{4}$ to $\mathrm{SBR}$, with similar results having been observed by Satraphan et al. ${ }^{44}$ and Kochthongrasamee et al. ${ }^{45}$ who suggested that the homopolymerization was more pronounced than the graft copolymerization at higher monomer concentrations, and thus, the free $\mathrm{PD}_{4}$ increased and the silicon content in the SBR- $g$ - $\mathrm{D}_{4}$ decreased.

For the practical silicon content (PCS) and grafting efficiency of SBR (GER), these increased with increasing the weight ratio of $\mathrm{D}_{4}$ to SBR; however, they remained constant when the weight ratio of $\mathrm{D}_{4}$ to SBR was higher than 0.20 , as shown in Fig. 4 . The constant silicon content and GER were $1.72 \%$ and $0.13 \mathrm{wt} \%$ when the weight ratio of $\mathrm{D}_{4}$ to SBR was 0.20 . This is due to the fact that the inter-molecule crosslinking reactions of SBR probably occurred throughout the grafting polymerization, ${ }^{10}$ and the formed cross linking network structure could prevent the free $\mathrm{D}_{4}$ monomers from reacting with the SBR molecular chains, resulting in the constant GER at the higher weight ratio of $\mathrm{D}_{4}$ to SBR.

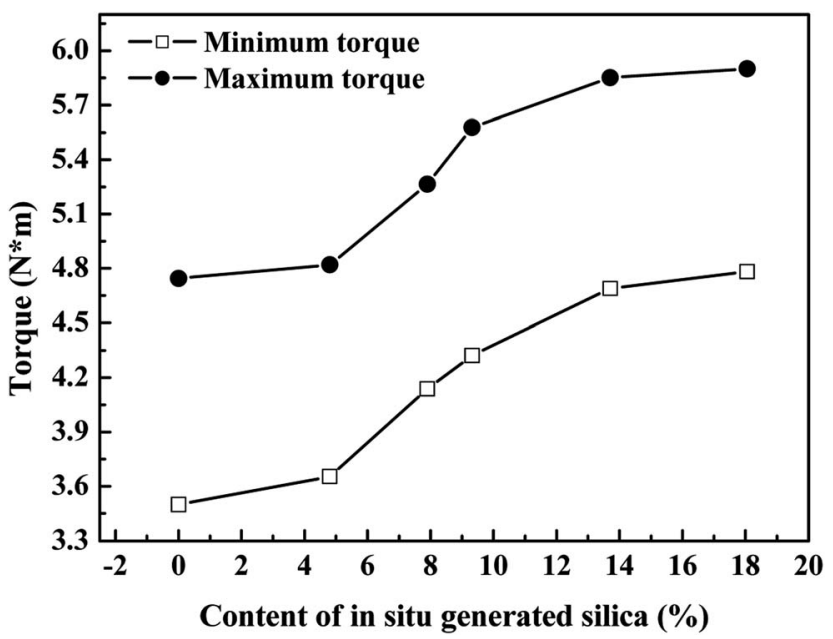

Fig. 11 Effects of in situ generated silica content on the torque of reinforced SBR-g-D $D_{4}$ vulcanizates.

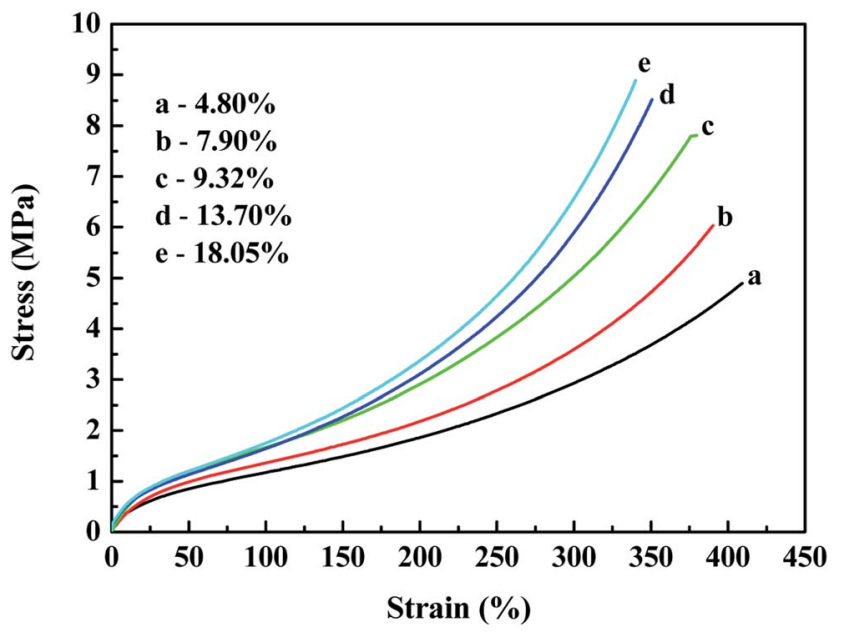

Fig. 12 Effects of the silica content on the stress-strain behavior of silica reinforced SBR-g- $D_{4}$.

3.2.2 Curing characteristics of SBR- $g-D_{4}$ vulcanizates. Scorch time $\left(t_{\mathrm{s} 2}\right)$ and optimum cure time $\left(t_{90}\right)$ of the SBR- $g-\mathrm{D}_{4}$ vulcanizates are shown in Fig. $5 t_{\mathrm{s} 2}$ is a measure of the time to premature vulcanization while $t_{90}$ is the optimum cure time of the vulcanizates. It can be seen that both the $t_{\mathrm{s} 2}$ and $t_{90}$ of the vulcanizates were prolonged with increasing the weight ratio of $\mathrm{D}_{4}$ to SBR. This might be due to the high polarities of $-\mathrm{Si}-\mathrm{O}-\mathrm{Si}-$ groups which interfere with the vulcanization, that is, some of the $-\mathrm{Si}-\mathrm{O}-\mathrm{Si}$ - groups in the $\mathrm{D}_{4}$ are assumed to have interacted with $-\mathrm{C}=\mathrm{C}-$ groups in the molecular chains of $\mathrm{SBR}$; the remaining free $-\mathrm{Si}-\mathrm{O}-\mathrm{Si}$ groups could possibly form hydrogen bonds with polar accelerators, causing accelerator adsorption on the polar surface. ${ }^{46}$

The value of $t_{90}-t_{10}$ can represent the increasing speed of the degree of rubber crosslinking. As also shown in Fig. 5, the value of $t_{90}-t_{10}$ increased significantly with increasing the weight ratio of $\mathrm{D}_{4}$ to $\mathrm{SBR}$, and this remained constant when

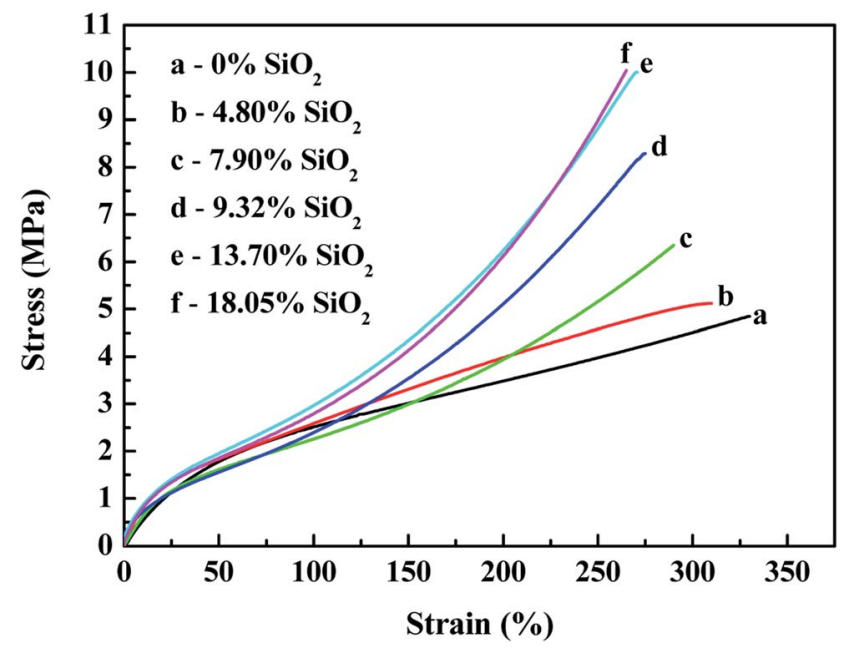

Fig. 13 Effects of the silica content on the stress-strain behavior of in situ generated silica reinforced SBR-g- $D_{4}$. 
Table 4 Effects of the silica content on the tensile strength and elongation at break of the silica reinforced SBR-g-D 4 and in situ generated silica reinforced SBR-g-D $D_{4}$ vulcanizates

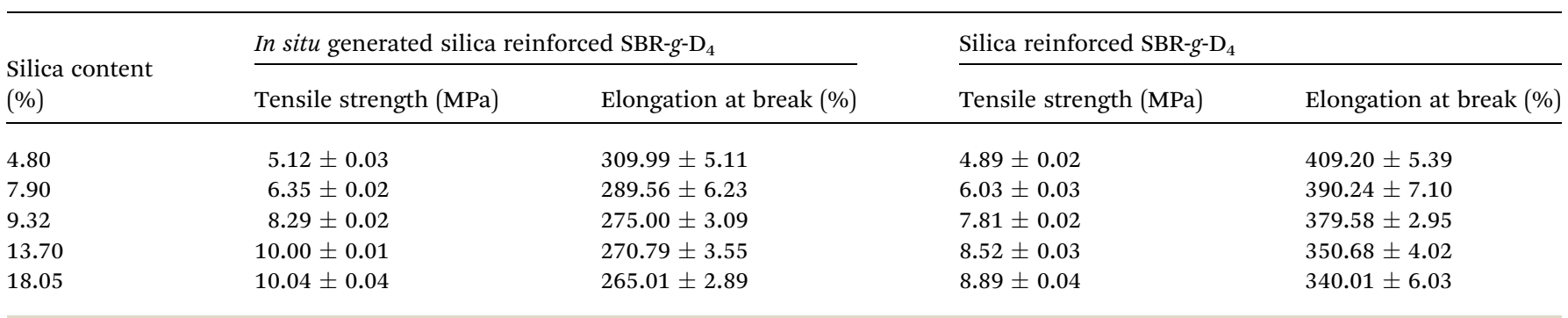

the weight ratio of $\mathrm{D}_{4}$ to SBR was higher than 0.20. Compared with the crosslinking degree of pristine SBR, the crosslinking degree of SBR- $g$ - $\mathrm{D}_{4}$ containing the additional $-\mathrm{Si}-\mathrm{O}-\mathrm{Si}-$ linkage crosslinking caused by the ring-opening polymerization in the SBR- $g$ - $\mathrm{D}_{4}$ (ref. 47) is enhanced, and thus, the greater the SBR- $g-\mathrm{D}_{4}$ content, the faster the increasing speed of the degree of rubber crosslinking. Meanwhile, the SBR-g$\mathrm{D}_{4}$ content is determined by the GER which is shown in Fig. 4; as a result, the changes in $t_{90}-t_{10}$ are consistent with the GER data.

Fig. 6 shows the effects of the weight ratio of $\mathrm{D}_{4}$ to SBR on the maximum torque (MH) and minimum torque (ML) of the SBR-g$\mathrm{D}_{4}$; it shows that the $\mathrm{MH}$ and ML increased with increasing the weight ratio of $\mathrm{D}_{4}$ to $\mathrm{SBR}$. The small number of grafted $\mathrm{D}_{4}$ chains could enhance interaction between SBR molecular chains, causing the increased $\mathrm{MH}$ and ML.

3.2.3 Mechanical properties of $\mathrm{SBR}-g$ - $\mathrm{D}_{4}$ vulcanizates. Fig. 7 shows the effects of the weight ratio of $\mathrm{D}_{4}$ to SBR on the stress-strain behavior of the SBR-g- $\mathrm{D}_{4}$ vulcanizates. It can be seen that the high $\mathrm{D}_{4}$ content in the SBR-g- $\mathrm{D}_{4}$ is beneficial in improving the modulus of the SBR-g- $\mathrm{D}_{4}$ vulcanizates, which reflects an increase in the cross-linking density of SBR-g-D $\mathrm{D}_{4}$ chains. $^{48}$

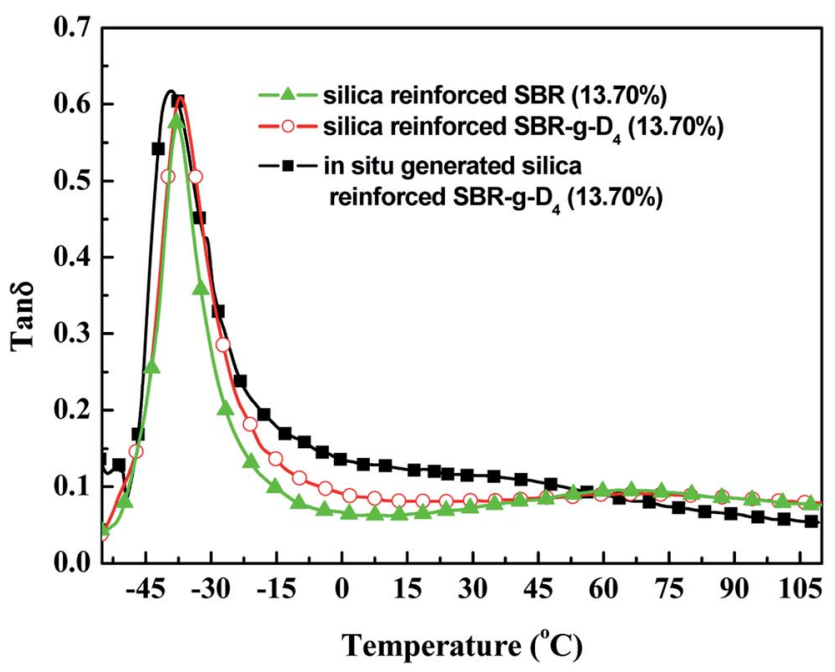

Fig. 14 Temperature dependence of $\tan \delta\left(-50\right.$ to $\left.110^{\circ} \mathrm{C}\right)$ for silica reinforced SBR, SBR- $g-D_{4}$ and in situ generated silica reinforced SBR$g-D_{4}$.
The effects of the weight ratio of $\mathrm{D}_{4}$ to SBR on the tensile strength, elongation at break and the modulus at $100 \%$ elongation are presented in Fig. 8 and 9. These show that the tensile strength and modulus at $100 \%$ elongation increased with increasing the weight ratio of $\mathrm{D}_{4}$ to $\mathrm{SBR}$, but the elongation at break decreased with increasing the weight ratio of $\mathrm{D}_{4}$ to $\mathrm{SBR}$, while all remained reasonably constant when the weight ratio of $\mathrm{D}_{4}$ to SBR was higher than 0.20.

Compared with the SBR vulcanizates, the enhancement of the tensile strength and modulus at $100 \%$ elongation in the SBR- $g$ - $\mathrm{D}_{4}$ vulcanizates may be due to the higher crosslinking degree than in SBR, that is, the crosslinking degree of the SBR-g$\mathrm{D}_{4}$ vulcanizates can be mainly attributed to two contributions: sulfur crosslinkage and $\mathrm{D}_{4}$ crosslinkage; these lead to the strengthening of the interface which could subsequently promote an easier stress transfer across the molecular chains. ${ }^{49}$ At the same time, the higher crosslinking density of SBR-g- $-\mathrm{D}_{4}$ increases the rigidity of rubber molecular chains, resulting in a decrease in the elongation at break.

The effects of the $\mathrm{D}_{4}$ content on the silica content, curing characteristics and mechanical properties of SBR-g-D $\mathrm{D}_{4}$ having been thoroughly investigated, it was found that the optimal weight ratio of $\mathrm{D}_{4}$ to SBR is 0.20 . The SBR-g- $\mathrm{D}_{4}$ latex with the optimal weight ratio was then mixed with a certain amount of TEOS at $50{ }^{\circ} \mathrm{C}$.

\subsection{Sol-gel reaction of TEOS in the SBR-g-D $-\mathrm{D}_{4}$ latex}

3.3.1 In situ generated silica content in reinforced SBR-g$D_{4}$ and utilization efficiency of TEOS. Fig. 10 shows the effect of the weight of TEOS (5.00-45.00 g) on the in situ generated silica $\left(\mathrm{SiO}_{2}\right)$ content in the reinforced SBR- $g-\mathrm{D}_{4}$ at $50{ }^{\circ} \mathrm{C}$, with the TEOS being added after the graft copolymerization.

The in situ generated silica content increased with increasing TEOS weight, although it remained constant after the weight of TEOS was more than $35 \mathrm{~g}$. As the in situ silica was generated by the sol-gel reaction of TEOS, the silica content was thus controlled by the weight of TEOS and the in situ formed silica content increased with increasing TEOS weight. However, this sol-gel technique may be restricted by the amount of $\mathrm{D}_{4}$ grafted SBR due to the polarity differences between SBR and silica. ${ }^{50}$ For excessively TEOS filled composites (where the weight of TEOS was higher than $35 \mathrm{~g}$ ), a constant in situ silica content was observed. This is due to the fact that, relative to the weight of TEOS, the weight of the SBR- $g-\mathrm{D}_{4}$ is limited, and as a result, the extra in situ silica generated from TEOS agglomerates and 
separates out from the SBR- $g$ - $\mathrm{D}_{4}$ latex, resulting in the relatively constant in situ generated silica content. Similarly, with the limited amount of SBR- $g$ - $\mathrm{D}_{4}$ mixed with the TEOS, the utilization of TEOS decreased with the increasing weight of TEOS, and then became constant, which is also shown in Fig. 10.

3.3.2 Curing characteristics of the in situ generated silica reinforced SBR- $\boldsymbol{g}-\mathbf{D}_{\mathbf{4}}$ vulcanizates. Table 3 shows the effect of in situ generated silica content on the curing time of reinforced SBR- $g-\mathrm{D}_{4}$. This shows that the $t_{\mathrm{s} 2}$ and $t_{90}$ increased with increasing in situ generated silica $\left(\mathrm{SiO}_{2}\right)$ content, which is attributed to the absorption of the accelerator by the $-\mathrm{OH}$ groups on the in situ generated $\mathrm{SiO}_{2}$ surface; this consequently lowered the accelerator activity and slowed down the sulfur vulcanizing reaction, resulting in the delayed curing time of the in situ generated silica reinforced SBR- $g-\mathrm{D}_{4}{ }^{.1}$

With respect to the $t_{90}-t_{10}$, it increased with increasing weight of TEOS. It is possible that the in situ generated $\mathrm{SiO}_{2}$ was grafted onto the SBR- $g-\mathrm{D}_{4}$ chains by the chemical bond between $-\mathrm{Si}-\mathrm{O}$ - groups in SBR- $g-\mathrm{D}_{4}$ and $\mathrm{SiO}_{2}$, which could increase the crosslinking degree of SBR- $g$ - $\mathrm{D}_{4}$, thereby resulting in the increase in $t_{90}-t_{10}$.
Fig. 11 shows the effect of the in situ generated $\mathrm{SiO}_{2}$ content on the torque (ML and $\mathrm{MH}$ ) of reinforced SBR- $g-\mathrm{D}_{4}$ vulcanizates. The $\mathrm{ML}$ and $\mathrm{MH}$ are closely related to the interaction between SBR- $g-\mathrm{D}_{4}$ and $\mathrm{SiO}_{2}$. The ML and $\mathrm{MH}$ were found to be increased with increasing silica content, indicating a good interaction between SBR- $g-\mathrm{D}_{4}$ and $\mathrm{SiO}_{2}$. This is due to the improvement of the interaction between the SBR- $g-\mathrm{D}_{4}$ and $\mathrm{SiO}_{2}$ by the $-\mathrm{Si}-\mathrm{O}-\mathrm{Si}-$ groups in the molecular chains of the SBR- $g-\mathrm{D}_{4} \cdot{ }^{52}$ For excessively silica filled composites (the content of silica was higher than 13.70\%), constant ML and MH were observed, due to the fact that, relative to the in situ silica content, the -Si-O- groups in the SBR- $g-\mathrm{D}_{4}$ are limited. As a result, an excess amount of in situ generated silica cannot be inserted into the networks of SBR- $g$ $\mathrm{D}_{4}$ molecular chains to enhance the interaction between SBR- $g$ $\mathrm{D}_{4}$ molecular chains and $\mathrm{SiO}_{2}$, resulting in the relatively constant ML and MH when the silica content is higher than $13.70 \%$.

3.3.3 Mechanical properties of the silica reinforced SBR- $g$ $\mathrm{D}_{\mathbf{4}}$ and in situ generated silica reinforced $S B R-\boldsymbol{g}-\mathrm{D}_{\mathbf{4}}$ vulcanizates. The effects of the silica content on the stress-strain behavior of the silica reinforced SBR and in situ generated silica reinforced

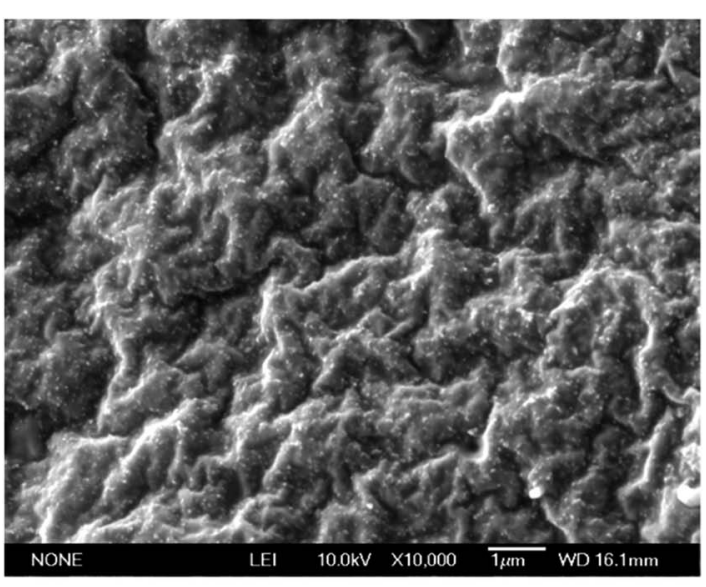

(a)

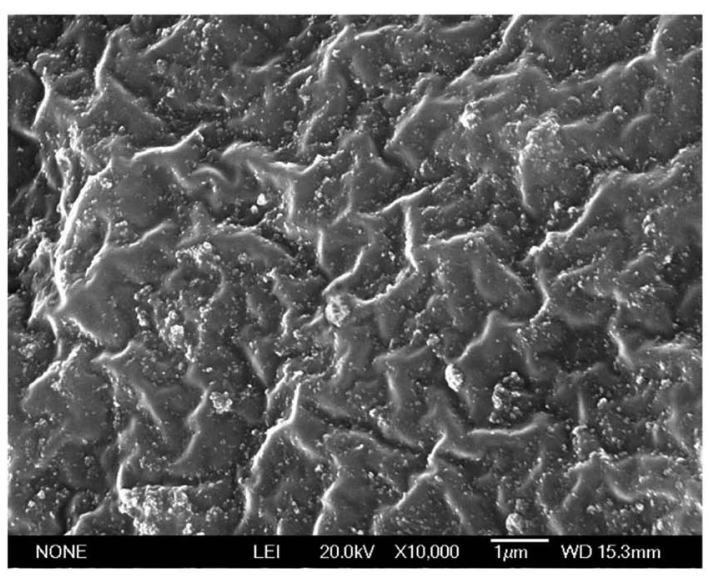

(c)

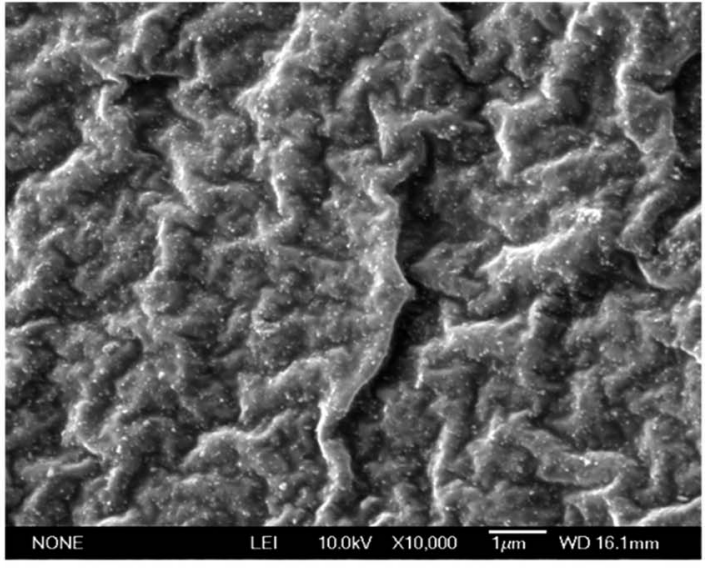

(b)

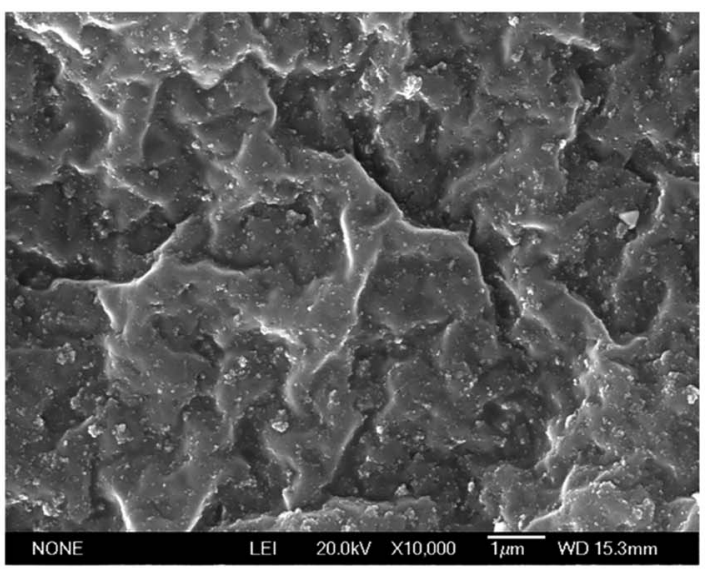

(d)

Fig. 15 Morphological images of the tensile fracture surface of in situ generated silica reinforced SBR-g-D4 with a varying silica content: (a) 7.9\%, (b) $9.32 \%$, (c) $13.7 \%$, and (d) $18.05 \%$. 
SBR- $g-\mathrm{D}_{4}$ are presented in Fig. 12 and 13, respectively, and the detailed tensile strength and elongation at break data are summarized in Table 4.

Fig. 12 and 13 both show that the stress-strain properties of the reinforced SBR- $g$ - $\mathrm{D}_{4}$ composites gradually improve with an increase in the silica content in the composite. The improvement in the mechanical properties is attributed to the rubber filler interaction. At the same time, the stronger modulus in the in situ generated silica reinforced $\mathrm{SBR}-g-\mathrm{D}_{4}$ vulcanizates is due to more regularity and the presence of entanglements.

Table 4 shows that the tensile strength increased with increasing in situ generated $\mathrm{SiO}_{2}$ content, and peaked at an $\mathrm{SiO}_{2}$ content of $13.70 \%$, becoming relatively constant at the higher $\mathrm{SiO}_{2}$ content. This is due to the reinforcement effect of in situ generated silica particles on the $\mathrm{SBR}-g-\mathrm{D}_{4}$ matrix networks. ${ }^{53}$ This result correlates well with the $\mathrm{MH}$ and $\mathrm{ML}$ data for the reinforced $\mathrm{SBR}-\mathrm{g}-\mathrm{D}_{4}$ noted above, due to the limited -Si-Ofunctional groups in the SBR- $g$ - $\mathrm{D}_{4}$. The elongation at break of the reinforced $S B R-g-D_{4}$ vulcanizates decreased with the increasing in situ generated silica content. This is due to more silica-SBR- $g$ - $\mathrm{D}_{4}$ interactions and higher crosslink densities. ${ }^{54}$ At the same time, the tensile strength of the in situ generated silica reinforced SBR- $g-\mathrm{D}_{4}$ was higher than that of the silica reinforced SBR- $g$ - $\mathrm{D}_{4}$, which is attributed to the higher crosslinking degree in the SBR- $g-\mathrm{D}_{4}$ matrix and the strong chemical bond between SBR- $g$ - $\mathrm{D}_{4}$ molecular chains and in situ generated silica.

All these results may also prove that SBR- $g$ - $\mathrm{D}_{4}$ can generate a chemical interaction with in situ generated $\mathrm{SiO}_{2}$ in the silicareinforced $\mathrm{SBR}-\mathrm{g}-\mathrm{D}_{4}$, according to the mechanism proposed in Scheme $1 .^{55,56}$

3.3.4 Dynamic mechanical analysis of the silica reinforced SBR-g- $-\mathrm{D}_{4}$ and in situ generated silica reinforced SBR-g-D $\mathrm{D}_{4}$ vulcanizates. It was reported that the loss tangent $(\tan \delta)$ at 50 $80{ }^{\circ} \mathrm{C}$ is an indication of tire rolling resistance, and the lower the value of $\tan \delta$ at $50-80^{\circ} \mathrm{C}$, the better the rolling resistance of tires. In a laboratory scale test, the tan $\delta$ at -20 to $0{ }^{\circ} \mathrm{C}$ of the vulcanizates is an indication of wet skid resistance, and the higher the value of $\tan \delta$ at -20 to $0{ }^{\circ} \mathrm{C}$, the better the wet skid resistance of tires. ${ }^{56,57}$

The $\tan \delta$ values of the silica reinforced SBR, SBR- $g-\mathrm{D}_{4}$ and in situ generated silica reinforced SBR-g- $\mathrm{D}_{4}$ vulcanizates are shown in Fig. 14. Compared with the $\tan \delta$ value of silica reinforced SBR vulcanizates, the $\tan \delta$ value at -20 to $0{ }^{\circ} \mathrm{C}$ of the silica reinforced SBR- $g$ - $\mathrm{D}_{4}$ vulcanizates was higher, indicating the better wet skid resistance of the silica reinforced SBR- $g-\mathrm{D}_{4}$ vulcanizates. At the same time, the tan $\delta$ value at -20 to $0{ }^{\circ} \mathrm{C}$ of the in situ generated silica reinforced SBR- $g$ - $\mathrm{D}_{4}$ vulcanizates was highest of all, indicating an increased wet skid resistance, while the tan $\delta$ at $50-80{ }^{\circ} \mathrm{C}$ of the in situ generated silica reinforced SBR- $g$ - $\mathrm{D}_{4}$ vulcanizates was lower, implying a decrease in rolling resistance. This may be attributed to a strong interaction between SBR and in situ generated silica and the additional linkages created by $\mathrm{D}_{4}$.

\subsection{Morphology of the in situ generated silica reinforced SBR- $g-D_{4}$ vulcanizates}

The morphological behavior of the tensile fracture surface (at $7.9 \%, 9.32 \%, 13.7 \%$, and $18.05 \%$ in situ generated silica content) was analyzed by a scanning electron microscopy (SEM) study, as shown in Fig. 15(a), (b), (c), and (d), respectively. The SEM images clearly indicate the good silica filler dispersion in all the reinforced SBR- $g-D_{4}$ vulcanizates. This is due to the fact that SBR- $g-\mathrm{D}_{4}$ may act as a compatibilizer between ungrafted SBR and the in situ generated silica particles, which increases the dispersion of the silica particles to a greater extent. However, compared with the fracture surfaces seen in Fig. 15(c) and (d), the in situ generated silica reinforced SBR- $g-\mathrm{D}_{4}$ vulcanizates (Fig. 15(a) and (b)) exhibit a rugged surface when the silica content is lower than $9.32 \%$. This is because of the higher crosslinking degree in the SBR- $g-\mathrm{D}_{4}$ matrix and the strong chemical bond between SBR- $g-\mathrm{D}_{4}$ molecular chains and in situ generated silica, which improves the plasticity of in situ generated silica reinforced SBR. ${ }^{58}$

\section{Conclusions}

A new in situ generated silica reinforced SBR- $g$ - $D_{4}$ vulcanizate has been developed from SBR latex through the grafting and sol-gel reaction of TEOS. The chemical structures of SBR- $g-\mathrm{D}_{4}$ and in situ generated silica reinforced SBR- $g$ - $\mathrm{D}_{4}$ were assessed by FTIR, Raman and XPS analysis. After grafting, the constant silicon content and GER were $1.72 \%$ and $0.13 \mathrm{wt} \%$ when the weight ratio of $\mathrm{D}_{4}$ to SBR was 0.20 ; under this condition, the tensile strength of SBR- $g-\mathrm{D}_{4}$ vulcanizates could reach $4.84 \mathrm{MPa}$. The SBR- $g-\mathrm{D}_{4}$ was then reinforced by the in situ generated silica formed by the sol-gel reaction of TEOS in latex; the constant in situ generated silica content was $18.05 \%$, and the tensile strength of the in situ generated silica reinforced SBR- $g-\mathrm{D}_{4}$ was found to have been significantly enhanced. The tensile strength of the in situ generated silica reinforced SBR- $g-\mathrm{D}_{4}$ vulcanizates was increased significantly compared to that of pristine rubber vulcanizates, due to the formation of chemical bonds between -Si-O- groups in SBR- $g-\mathrm{D}_{4}$ and in situ generated silica. SEM images clearly indicate the good silica filler dispersion of all of the reinforced SBR- $g-\mathrm{D}_{4}$ vulcanizate matrices.

\section{Conflicts of interest}

There are no conflicts to declare.

\section{Acknowledgements}

The authors are grateful for support and funding from the National Natural Science Foundation of China (No. 51603168), and the Natural Science Foundation of Shaanxi Province (No. 2017JQ2011).

\section{References}

1 A. Tunlert, P. Prasassarakich and S. Poompradub, Effect of Modified Silica Particles with Phenyltriethoxysilane on Mechanical and Thermal Properties of Natural Rubber Composites, Macromol. Symp., 2015, 354, 62-68.

2 Y. Li, B. Han, L. Liu, F. Zhang and S. Wen, Surface modification of silica by two-step method and properties of 
solution styrene butadiene rubber (SSBR) nanocomposites filled with modified silica, Compos. Sci. Technol., 2013, 88, 69-75.

3 K. Stockelhuber, A. Svistkov, A. Pelevin and G. Heinrich, Impact of filler surface modification on large scale mechanics of styrene butadiene/silica rubber composites, Macromolecules, 2011, 44(11), 4366-4381.

4 C. Lan, S. ha, K. Tridib and T. Lei, Synergistic reinforcement of silanized silica-graphene oxide hybrid in natural rubber for tire-tread fabrication: a latex based facile approach, Composites, Part B, 2019, 161, 667-676.

5 C. Sun, S. Wen and H. Ma, Improvement of Silica Dispersion in Solution Polymerized Styrene-Butadiene Rubber via Introducing Amino Functional Groups, Ind. Eng. Chem. Res., 2019, 58, 1454-1461.

6 S. Prasertsri and N. Rattanasom, Mechanical and damping properties of silica/natural rubber composites prepared from latex system, Polym. Test., 2011, 30, 515-526.

7 K. Sengloyluan, K. Sahakaro, W. K. Dierkes and J. W. M. Noordermeer, Silane grafted natural rubber and its compatibilization effect on silica-reinforced rubber tire compounds, eXPRESS Polym. Lett., 2017, 11, 1003-1022.

8 B. C. Zhong, Z. X. Jia, D. C. Hu, Y. F. Luo, D. M. Jia and F. Liu, Enhancing interfacial interaction and mechanical properties of styrene-butadiene rubber composites via silica-supported vulcanization accelerator, Composites, Part A, 2017, 96, 129136.

9 S. Pongsathit and C. Pattamaprom, Irradiation grafting of natural rubber latex with maleic anhydride and its compatibilization of poly(lactic acid)/natural rubber blends, Radiat. Phys. Chem., 2018, 144, 13-20.

10 B. Tian, W. Dong and Y. G. Liu, Grafting poly(vinyl alcohol) onto polybutadiene rubber latex particles by pre-irradiation, Radiat. Phys. Chem., 2017, 135, 81-87.

11 N. H. Yusof, K. Kosugi, T. K. Song and S. Kawahara, Preparation and characterization of poly(stearyl methacrylate) grafted natural rubber in latex stage, Polymer, 2016, 88, 43-51.

12 P. Saramolee, N. Lopattananon and K. Sahakaro, Preparation and some properties of modified natural rubber bearing grafted poly(methyl methacrylate) and epoxide groups, Eur. Polym. J., 2014, 56, 1-10.

13 P. Juntuek, C. Ruksakulpiwat, P. Chumsamrong and Y. Ruksakulpiwat, Glycidyl methacrylate grafted natural rubber: synthesis, characterization, and mechanical property, J. Appl. Polym. Sci., 2011, 122, 3152-3159.

14 N. T. Ha, K. Kaneda, Y. Naitoh, L. Fukuhara, K. Kosugi and S. Kawahara, Preparation and graft-copolymerization of hydrogenated natural rubber in latex stage, J. Appl. Polym. Sci., 2015, 132, 42435-42442.

15 N. Pukkate, T. Kitai, Y. Yamamoto, T. Kawazura and S. Kawahara, Nano-matrix structure formed by graftcopolymerization of styrene onto natural rubber, Eur. Polym. J., 2007, 43, 3208-3214.

16 C. J. Yin and Q. Y. Zhang, Studies on preparation and properties of vinyltriethoxysilane-grafted styrene-butadiene rubber, J. Appl. Polym. Sci., 2011, 119, 2808-2814.
17 M. Takamura, T. Yamauchi and N. Tsubokawa, Grafting and crosslinking reaction of carboxyl-terminated liquid rubber with silica nanoparticles and carbon black in the presence of Sc(OTf $)_{3}$, React. Funct. Polym., 2008, 68, 1113-1118.

$18 \mathrm{~W}$. Chueangchayaphan, N. Chueangchayaphan and S. M. VTanrattanakul, Influences of the grafting percentage of natural rubber-graft-poly(2-hydroxyethyl acrylate) on properties of its vulcanizates, Polym. Int., 2018, 67, 739-746.

19 N. H. Yusof, K. Kosugi, T. K. Song and S. Kawahara, Preparation and characterization of poly(stearyl methacrylate) grafted natural rubber in latex stage, Polymer, 2016, 88, 43-51.

20 C. Zhang, C. Man, Y. Pan, W. Wang, L. Jiang and Y. Dan, Toughening of polylactide with natural rubber grafted with poly(butyl acrylate), Polym. Int., 2011, 60, 1548-1555.

21 J. Peng, M. L. Wang, J. L. Qiao and G. S. Wei, Radiationinduced grafting polymerization of MMA onto polybutadiene rubber latex, Radiat. Phys. Chem., 2005, 72, 739-743.

22 N. C. Dafader, M. E. Haque, F. Akhtar and M. U. Ahmad, Study on grafting of different types of acrylic monomers onto natural rubber by $\gamma$-rays, Radiat. Phys. Chem., 2006, 75, 168-172.

23 C. C. Ferraz, G. H. Varca, J. C. Ruiz, P. S. Lopes and E. Bucio, Radiation-grafting of thermo- and $\mathrm{pH}$-responsive poly $(\mathrm{N}$ vinylcaprolactam-co-acrylic acid) onto silicone rubber and polypropylene films for biomedical purposes, Radiat. Phys. Chem., 2014, 97, 298-303.

24 T. Ohashi, A. Tohsan and Y. Ikeda, Role of in situ generated silica for rubber science and technology, Polym. Int., 2017, 66, 250-259.

25 B. P. Kapgate, C. Y. Das, A. Das, D. Basu, S. Wiessner, U. Reuter and G. Heinrich, Reinforced chloroprene rubber by in situ generated silica particles: Evidence of bound rubber on the silica surface, J. Appl. Polym. Sci., 2016, 133(30), 43717-43726.

26 Q. Y. Li, X. Li, D. Lee, Y. Fan, B. U. Nam, J. E. Lee and U. R. Cho, Hybrid of bamboo charcoal and silica by tetraethoxysilane hydrolysis over acid catalyst reinforced styrene-butadiene rubber, J. Appl. Polym. Sci., 2018, 135, 46219-46225.

27 T. Atitaya, K. Ryota and Y. Ikeda, A model filler network in nanocomposites prepared by in situ silica filling and peroxide cross-linking in natural rubber latex, Colloid Polym. Sci., 2015, 293, 2083-2093.

28 F. Bignotti, S. Borsacchi, R. de Santis, M. Geppi, M. Messori and U. P. Sudhakaran, Interrelation between preparation conditions, structure, and mechanical reinforcement in isoprene rubber filled with in situ generated silica, J. Appl. Polym. Sci., 2012, 125, 1398-1412.

29 N. Sakdinun, Y. Satit, C. Supphathee, Y. Toshiyuki and N. T Takashi, Chawalit. Mesostructured natural rubber/in situ formed silica nanocomposites: a simple way to prepare mesoporous silica with hydrophobic properties, Microporous Mesoporous Mater., 2018, 259, 79-88.

30 V. Raman, A. D. Sankar and K. W. Stoeckelhuber, Improvement of mechanical performance of solution 
styrene butadiene rubber by controlling the concentration and the size of in situ derived sol-gel silica particles, $R S C$ Adv., 2016, 6, 33643-33655.

31 T. Sittiphan, P. Prasassarakich and S. Poompradub, Styrene grafted natural rubber reinforced by in situ silica generated via sol-gel technique, Mater. Sci. Eng., B, 2014, 181, 39-45.

32 N. Watcharakul, S. Poompradub and P. Prasassarakich, In situ silica reinforcement of methyl methacrylate grafted natural rubber by sol-gel process, J. Sol-Gel Sci. Technol., 2011, 58, 407-418.

33 C. Yin and Q. Zhang, In situ silica reinforcement of vinyltriethoxysilane-grafted styrene butadiene rubber by sol-gel process, J. Appl. Polym. Sci., 2013, 128, 2262-2268.

34 C. Yin, Q. Zhang and J. Liu, Preparation, properties of in situ silica modified styrene butadiene rubber and its silica-filled composites, Polym. Compos., 2018, 39, 22-28.

35 J. Liang, L. He, W. Li and H. Luo, Synthesis and analysis of properties of a new core-shell silicon-containing fluoroacrylate latex, Polym. Int., 2009, 58, 1283-1290.

36 S. Jiang and X. L. TQiu, Kinetic study on the ring-opening polymerization of octamethylcyclotetrasiloxane $\left(D_{4}\right)$ in miniemulsion, Polymer, 2010, 51, 4087-4094.

37 C. Lia, Y. Wang, Z. Yuan and L. Ye, Construction of sacrificial bonds and hybrid networks in EPDM rubber towards mechanical performance enhancement, Appl. Surf. Sci., 2019, 484, 616-627.

38 K. Huang, Y. Liu and D. Wu, Synthesis and characterization of polyacrylate modified by polysiloxane latexes and films, Prog. Org. Coat., 2014, 77, 1774-1779.

39 W. Kangwansupamonko, R. G. Gilbert and S. Kiatkamjornwong, Modification of natural rubber by grafting with hydrophilic vinyl monomers, Macromol. Chem. Phys., 2005, 206, 2450-2460.

40 R. Scotti, L. Wahba, M. Crippa, M. Arienzo and R. Donetti, Rubber-silica nanocomposites obtained by in situ sol-gel method: particle shape influence on the filler-filler and filler-rubber interactions, Soft Matter, 2012, 8, 2131-2143.

41 N. J. Trujillo, Q. G. Wu and K. K. Gleason, Ultralow Dielectric Constant Tetravinyltetramethylcyclotetrasiloxane Films Deposited by Initiated Chemical Vapor Deposition (iCVD), Adv. Funct. Mater., 2010, 20, 607-616.

42 P. L. Lamaa, C. Ferronato, S. Prakash and L. Fine, Photocatalytic oxidation of octamethylcyclotetrasiloxane $\left(D_{4}\right)$ : towards a better understanding of the impact of volatile methyl siloxanes on photocatalytic systems, Appl. Catal., B, 2014, 156-157, 438-446.

43 K. Huang, Y. L. Liu and D. F. Wu, Synthesis and characterization of polyacrylate modified by polysiloxane latexes and films, Prog. Org. Coat., 2014, 77, 1774-1779.

44 P. Satraphan, A. Intasiri, V. Tangpasuthadol and S. Kiatkamjornwong, Effects of methyl methacrylate grafting and in situ silica particle formation on the morphology and mechanical properties of natural rubber composite films, Polym. Adv. Technol., 2009, 20, 473-486.

45 T. Kochthongrasamee, P. Prasassarakich and S. Kiatkamjornwong, Effects of redox initiator on graft copolymerization of methyl methacrylate onto natural rubber, J. Appl. Polym. Sci., 2006, 101, 2587-2601.

46 A. Tunlert, P. Prasassarakich and S. Poompradub, Effect of Modified Silica Particles with Phenyltriethoxysilane on Mechanical and Thermal Properties of Natural Rubber Composites, Macromol. Symp., 2015, 354, 62-68.

47 H. Yangthong, S. Pichaiyut, S. Jumrat, S. Wisunthorn and C. Nakason, Mechanical, thermal, morphological, and curing properties of geopolymer filled natural rubber composites, J. Appl. Polym. Sci., 2019, 136, 47346-47363.

48 C. J. Yin, Q. Y. Zhang and J. W. Gu, Cure characteristics and mechanical properties of styrene-butadiene rubber/ hydrogenatedacrylonitrile-butadiene rubber/silica composites, J. Polym. Res., 2011, 18, 2487-2494.

49 J. Jayadevan, R. Alexb and U. Gopalakrishnapanicker, Deproteinised natural rubber latex grafted poly(dimethylaminoethylmethacrylate)-poly(vinyl alcohol) blend membranes: synthesis, properties and application, Int. J. Biol. Macromol., 2018, 107, 1821-1834.

50 A. M. Shanmugharaj and H. Ryu, Influence of aminosilane functionalized carbon nantubes on the rheometric, mechanical, electrical and thermal degradation properties of epoxidized natural rubber nanocomposites, Polym. Int., 2013, 62, 1433-1441.

51 Y. Z. Song, J. H. Yu, D. Dai, L. X. Song and N. Jiang, Effect of silica particles modified by in situ and ex situ methods on the reinforcement of silicone rubber, Mater. Des., 2014, 64, 687-693.

52 C. J. Yin and Q. Y. Zhang, Free-radical emulsion copolymerization of styrene with butadiene and vinyl triethoxysilane with a cumene hydroperoxide redox initiator, J. Appl. Polym. Sci., 2019, 136, 47896-47902.

53 L. N. Carli, C. R. Roncato, A. Zanchet, R. S. Mauler, M. Giovanela, R. N. Brandalise and J. S. Crespo, Characterization of natural rubber nanocomposites filled with organoclay as a substitute for silica obtained by the conventional two-roll mill method, Appl. Clay Sci., 2011, 52, 56-61.

54 K. Sengloyluan, K. Sahakaro, W. K. Dierkes and J. W. M. Noordermeer, Silane grafted natural rubber and its compatibilization effect on silica-reinforced rubber tire compounds, eXPRESS Polym. Lett., 2017, 11, 1003-1022.

55 H. D. Luginsland, J. Frohlich and A. Wehmeier, Influence of different silanes on the reinforcement of silica-filled rubber compounds, Rubber Chem. Technol., 2002, 75, 563-579.

56 K. Sengloyluan, K. Sahakaro, W. K. Dierkes and J. W. M. Noordermeer, Silica-reinforced tire tread compounds compatibilized by using epoxidized natural rubber, Eur. Polym. J., 2014, 51, 69-79.

57 G. Arun and S. De, Dependence of Physical Properties and Processing Behavior of Blends of Silicone Rubber and Fluororubber on Blend Morphology, Rubber Chem. Technol., 2004, 77, 856-872.

58 S. Mohapatra, R. Alex and G. B. Nando, Cardanol grafted natural rubber: A green substitute to natural rubber for enhancing silica filler dispersion, J. Appl. Polym. Sci., 2016, 133, 43057-43062. 